\title{
Antonio de Lara Gavilán "Tono": genio e ingenio en las artes plásticas
}

\author{
Gema FernÁNDEZ-HoYa \\ Universidad Complutense de Madrid
}

Título: Antonio de Lara Gavilán Tono: genio e ingenio en las artes plásticas.

Resumen: Antonio de Lara Gavilán, integrante de la denominada "Otra Generación del 27", condensa dentro de su amplio legado profesional un gran número de obras como artista plástico. En las siguientes líneas se revisan y analizan las diferentes etapas del autor en dicho ámbito, aportando datos inéditos sobre su biografía y brillantes creaciones.
Title: Antonio de Lara Gavilán “Tono”: Genius and Ingeniousness in the Plastic Arts.

Abstract: Antonio de Lara Gavilán, member of the so-called the "Other Generation of'27", condenses within its ample professional legacy a great number of works as a plastic artist. In the following lines the different stages of the author's work under this scope are reviewed and analyzed unraveling new data on the author himself as well as on his remarkable creations.

Key words: Antonio de Lara Gavilán, Tono, The Other Generation of '27, Graphical Humour, Vanguard.

Date of Receipt: 24/3/2013.

Date of Approval: 27/5/2013.
Fecha de aceptación: 27/5/2013.

Palabras clave: Antonio de Lara Gavilán, Tono, Otra Generación del 27, humor gráfico, vanguardia.

Fecha de recepción: 24/3/2013.

(D)

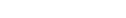


una intensa relación con el cine a partir de la posguerra: Enrique Jardiel Poncela, Antonio de Lara Gavilán “Tono”, Edgar Neville, Miguel Mihura y José López Rubio son los nombres de la "amistosa hermandad” a la que este último, en su Discurso de Ingreso en la RAE (1983), bautizó como la "Otra Generación del 27".

El quinteto antedicho protagoniza la sugestiva evolución del humor en las letras, los escenarios y las publicaciones periódicas durante las primeras décadas del siglo XX. Todos ellos comparten un contexto histórico común, además de una serie de influencias artísticas que podemos sintetizar en tres bloques: 1) las manifestaciones humorísticas en los medios de comunicación de masas: desde el teatro hasta el florecimiento de la prensa cómica, en la que empezarán a formarse con sus primeras colaboraciones; 2) la estimulante tutela de Gómez de la Serna; y 3) el rastro de las vanguardias europeas.

Definidos como "los cinco dedos de una mano maestra", todos ellos mantienen una postura ambigua ante la vida e imponen sobre sus textos una nueva concepción del mundo a través de lugares imprecisos, tiempos indefinidos y situaciones inauditas que rompen tópicos y clichés. Juegos y rupturas lingüísticas, pues, que plantean una honda crítica contra las normas establecidas. Caracterizados por su escepticismo, se enfrentan al mundo con la convicción de que no podrán cambiarlo, pero con el firme propósito de divertirse por el camino. De forma conjunta e independiente, "un sello indeleble, homogéneo y diverso a la vez, nadie es nada solo", otorgaron espacio, valor y permanencia al "Humor Nuevo", una de las vanguardias europeas surgidas a principios de la centuria en un intento de trivializar el arte y evitar la solemnidad.

Los humoristas del 27 mantuvieron una estrecha relación laboral y personal que les llevó a recalar en las mismas escuelas vitales y profesionales. Iniciaron su andadura participando en la prensa festiva y jocosa de los albores del XX con ilustraciones y breves relatos, para continuar después su trayectoria como novelistas y dramaturgos. Llegaron al "proyector de luna” por la puerta más grande, la de Hollywood. Hacia 1930, todos viajaron a Estados Unidos para trabajar en las versiones hispanas de los

1 José López Rubio, "La Otra Generación del 27”, Cuadernos de la Academia (1983), pp. 7-72 (p. 15).

2 José López Rubio, ibidem, p. 13. 
filmes norteamericanos, previas a la llegada de los subtítulos y el doblaje. Deslumbrados por el aprendizaje y la experiencia, regresaron a nuestro país con la intención de incorporarse a la industria cinematográfica; y así lo hicieron, con desigual fortuna y resultados. No obstante, sus carreras se mantendrán siempre unidas al teatro, gracias a unos excelentes libretos que les permitirán, en muchas ocasiones, sobrevivir y preservar su nombre en la república (o la dictadura) de las letras.

Pese a su meritoria y extensa obra artística, "la Otra Generación del 27 " ha sufrido un reconocimiento tardío y parcial, por motivos en los que no podemos abundar ahora. Resultaba especialmente llamativo el vacío bibliográfico en torno a uno de sus integrantes, Antonio de Lara Gavilán, conocido popularmente por su rúbrica artística: “Tono”. De hecho, hasta hace bien poco no contábamos con ninguna investigación en profundidad acerca del jiennense, que permanecía relegado en los anaqueles del olvido. La tesis doctoral de quien suscribe, presentada en abril de 2011 en la Universidad Complutense de $\mathrm{Madrid}^{3}$, contribuyó siquiera a romper esa dinámica, en unas páginas que suponen el primer trabajo específico sobre el perfil bio-bibliográfico de tan polifacética pluma. La citada investigación traza un acercamiento biográfico, además de atender a su trayectoria como escritor, artista plástico y, con más detalle, cineasta (director, guionista, dialoguista, argumentista, letrista musical, adaptador o actor). De todo ello deriva un buen número de aportaciones inéditas en los ámbitos citados, algunas de las cuales son expuestas en este artículo.

Antonio de Lara presenta una serie de diferencias notables con el resto de sus compañeros de grupo, relativas a su procedencia y formación. Los sucesos y episodios que jalonan su infancia y adolescencia colocan al humorista de forma muy diferente ante la vida, en general, y ante el hecho creativo, en particular. Tono no disfrutó de apoyos familiares ni profesionales que facilitaran sus inicios laborales. Tampoco le avala una cultura académica. Lidió, además, con una niñez de carencias materiales y afectivas. Todas estas circunstancias, unidas al reconocimiento que

3 Gema Fernández-Hoya La pirotecnia de la palabra. Antonio de Lara Gavilán "Tono" y el cine. Director de la Tesis Doctoral: Eduardo Rodríguez Merchán, Madrid, Facultad de Ciencias de la Información, Universidad Complutense de Madrid, 2011. 
obtuvo en su época, nos dan una idea de su talento, inteligencia y fascinante personalidad.

Su nacimiento se remonta a 1896 en Jaén. Con solo con cuatro años, Tono queda huérfano de padre y la familia se ve obligada a instalarse en Valencia para acceder a una escasísima pensión de viudedad y orfan$\mathrm{dad}^{4}$. Este varapalo provoca un giro crucial en su vida, no solo emocional, sino también material. A partir de este momento vive con su madre, un hermano ${ }^{5}$, la abuela materna y dos tías en un pequeño piso de la ciudad costera. Una enriquecedora convivencia, según declarará Tono, en tiempos venideros, por el conocimiento tan profundo que adquiere en estos años sobre las personalidades femeninas.

A su llegada a Madrid, con un agudizado sentido comercial y social, lucha por integrarse en un sector de aquella urbe cosmopolita y libre. Así, en las sucesivas posturas que manifiesta en el universo periodístico, literario o cinematográfico, levanta siempre un parapeto intangible sobre su intimidad, a través de una divertida y despreocupada imagen de sí mismo -intuición e inteligencia le sobran para este propósito-. En dicha argucia hace gala de tres de sus grandes cualidades: una imaginación desbordante, capacidad de improvisación y una sensibilidad extrema para mostrar el lado disparatado de la vida. Así, la imagen pública de Tono es divertida, pintoresca y no deja resquicio a los juicios morales o las valoraciones sobre sus orígenes. Su apariencia de hombre pletórico y feliz ante cualquier adversidad se completa con los testimonios de quienes disfrutaron de su compañía ${ }^{6}$ : bondadoso, generoso, educadísimo, inteligente, ingenioso, gran conversador....

4 Gonzalo de Lara, padre de Antonio de Lara, es funcionario del Ministerio de Hacienda y aunque su residencia familiar estaba localizada en Jaén, durante aquellos días se encontraba destinado en Valencia.

5 Hasta el momento los breves estudios dedicados a la vida de Tono narraban la muerte repentina de su hermano, Manuel de Lara, a los pocos años de llegar a Valencia, siendo ambos unos niños. Podemos ahora desmentir este dramático fallecimiento, pues los padrones municipales consultados entre 1904 y 1910 dan cuenta de ello.

6 Entre las personas que conocieron personalmente a Antonio de Lara o disfrutaron de su amistad, hemos tenido la suerte de entrevistar a Luis García-Berlanga, Rafael Azcona, Enrique Herreros (hijo), Ma Fernanda Thomas de Carranza, Enrique 
Su legado es muy extenso, hasta el punto de contradecir su pública animadversión al trabajo. Uno de sus sueños era triunfar en la gran pantalla y parece lograrlo con el increíble contrato que suscribió con la Metro Goldwing Mayer para formar parte del Departamento de Guionistas y colaborar en las versiones hispanas: sin haber escrito jamás un guión, ni saber una palabra de inglés. Recién casado con Leonor Orstein y compartiendo viaje con Luis Buñuel, rumbo al mismo destino, desembarca en Los Ángeles en 1930, donde participa en los diálogos adicionales de Min and Bill / La fruta amarga (A. Gregor, 1931) y rotula varias películas.

A su vuelta a España trabaja en más de treinta filmes pero no logrará el éxito que ansía. Durante la posguerra dirige dos largometrajes, Canción de Medianoche (1948) y Habitación para tres (1952), ninguno de los cuales obtiene repercusión. También aporta sus argumentos y guiones en Barrio (L. Vajda, 1947), Tres eran tres (E. García Maroto, 1955), Congreso en Sevilla (A. Román, 1955), El balcón de la luna (L. Saslavsky, 1962), La pandilla de los once (P. Lazaga, 1963) o la exitosa Adiós, cigüeña, adiós (M. Summers, 1971). No obstante, si bien intervino como adaptador de diálogos o letrista musical en algunas películas, sus trabajos más destacables son aquellos en los que se ocupa de los diálogos adicionales. Con otras palabras: estos últimos largometrajes resultan poco atractivos, faltos de ritmo y en la mayoría de las ocasiones de argumento manido, pero los diálogos de Tono brillan por sí solos. Con su ingenio logra reavivar la narración durante unos minutos en títulos como Olé Torero (B. Perojo, 1949), Torrejón City (L. Klimovsky, 1962), Cuatro bodas y pico (F. Catalán, 1967) o ¿Es usted mi padre? (A. Giménez Rico, 1971), entre otros.

La dramaturgia es otro de los caminos que recorrió Antonio de Lara. Además de escribir más de una decena de novelas e infinidad de relatos cortos que aparecen en publicaciones periódicas. Su carrera teatral, al igual que las de sus compañeros, gana estatura a partir de los años cuarenta, en virtud de las comedias con las que transforman el panorama escénico del país. En 1939, Tono y Mihura redactan Ni pobre, ni rico, sino todo lo contrario (1939), una pieza que levanta las pasiones del público en sentidos opuestos. A este libreto le seguirían treinta y dos comedias: Rebeco

Llovet, Rafael de Penagos (hijo), Elvira Quintillá, Antonio Giménez-Rico, Manuel Alexandre o Jesús Franco. 
(1944), Guillermo Hotel (1945), Don Pío descubre la primavera (1946), Los mejores años de nuestra tía (1948), ;Qué bollo es vivir! (1950), La viuda es sueño (1952), Bárbara (1948), Anastasio (1958), El marido, la mujer y la muerte (1959), Crimen pluscuamperfecto (1956) o Al rico bombón Eladio (1959), escritas en solitario o en colaboración con autores como Jorge Llopis, Enrique Llovet o Eduardo Manzanos. Igualmente son destacables las doce adaptaciones teatrales de obras extranjeras, entre las que encontramos Bárbara (1948), Anastasio (1958), El marido, la mujer y la muerte (1959), Minouche (1960) o Caviar con lentejas (1965).

Aunque la faceta de Antonio de Lara más popular y de la que aún hoy se conserva algún recuerdo es la de humorista gráfico, cultivó varias disciplinas en la esfera de las Bellas Artes: escultor, pintor, ilustrador, director de publicaciones, humorista gráfico, cartelista y diseñador. Atendiendo a todos estos aspectos, podemos considerar a Tono un genuino y proteico plástico, particular sobre el que incidiremos en las próximas líneas.

Desde una edad muy temprana le atrae la escultura y siendo tan solo un niño comienza a moldear con el barro que recoge en la ribera del río: "las visitas de mi casa solían decir: este niño puede ser un artista". Poco después el dibujo se convierte en su gran afición. Sus frecuentes escapadas de la escuela, unidas a sus aptitudes naturales, empujarán a su madre a inscribirlo en la Escuela de Artes y Oficios de Valencia, que abandona al poco, rechazando, una vez más, todo academicismo. "No tuve maestros, ni estudios artísticos", rememoraba ya en su madurez ${ }^{8}$. Para el jiennense se confirmaba entonces que las directrices académicas no encajaban con su personalidad, por más que ya en aquella etapa prendiera, y con fuerza, la mecha artística, que ya no le abandonaría.

En su adolescencia muestra una mentalidad abierta y una tendencia renovadora frente a lo establecido. Declara públicamente su desinterés por los pintores valencianos clasicistas y celebra las ilustraciones del que se convertirá después en su compañero de redacción: Ricardo García, K-Hito, revolucionario dibujante gráfico que con su estilo lineal, rompe la tradición de lo curvo impuesta por Xaudaró y su escuela. Lara descubre a

7 Marino Gómez Santos, "Tono cuenta su vida", en la sección "Pequeña historia de grandes personajes", Pueblo, 8-XII-1959, p. 18.

8 Luis del Olmo, "Páginas de una vida", programa radiofónico en Radio Nacional de España, 17-I-1973. 
K-Hito con catorce años y con quince comienza a colaborar en la prensa local como dibujante y caricaturista. En 1912, Maximiliano Thous Orts 9 funda El Guante Blanco, semanario inofensivo ${ }^{10}$, elegante periódico en el que, desde el número inaugural, nuestro precoz humorista publica cada semana un dibujo, a rebufo de los distintos artículos o secciones. A partir de 1913, mejora su responsabilidad en la publicación. Su función no se limita ya a ilustrar textos ajenos, sino que también comienza a publicar portadas ${ }^{11}$. Su calidad con el lápiz es cada vez más apreciada y durante $1914^{12}$ sus dibujos se alternan con los de K-Hito. Este primer triunfo profesional también le permite afrontar trabajos como cartelista publicitario ${ }^{13}$.

Dos meses después de su estreno como ilustrador en prensa, da los primeros pasos en la revista satírica La Traca. Esta publicación, fundada por Manuel Llunc Soler, tiene un azaroso recorrido a través de los años, debido al sesgo crítico con que maneja los temas monárquicos y religiosos. El semanario sufre varias clausuras durante su edición, la más extensa entre 1887 y 1912 . Es en la segunda época cuando renace con el marbete de La Traca: semanari bilingüe festiu y llierari y Tono se suma a su equipo de redacción.

El jienense firma con su primer apellido en sus inicios en la prensa valenciana, pero la grafía se modificará con el paso de las semanas: se esque-

9 Algunos años después Maximiliano Thous funda en Valencia "Grandes Producciones Cinematográficas Españolas”, con la que produciría La Dolores (1923) y Moros y cristianos (1926), convirtiéndose así en uno de los nombres decisivos de los primeros años del cine español.

10 El Guante Blanco, semanario inofensivo se funda en Valencia el 12 de mayo de 1912 y expira en 1919.

11 Extraemos estos datos de la Hemeroteca de la Biblioteca Valenciana y Fondo Documental Navarro Cabanes en la Hemeroteca Municipal de Valencia. Tras la revisión completa de El Guante Blanco, podemos afirmar que la primera portada firmada por Tono corresponde al número 40, impreso el 9 de febrero de 1913. Se ocupa también de las portadas en los siguientes tres números y después alterna esta ocupación con las ilustraciones en páginas interiores.

12 Hemeroteca de la Biblioteca Valenciana. Encontramos ejemplos en distintos números del semanario a partir de 1914.

13 Ibidem. Como ejemplo hemos localizado su cartel para "Jarabes Sanz", que aparece a toda página en todos los números de El Guante Blanco entre septiembre y octubre de 1916. 

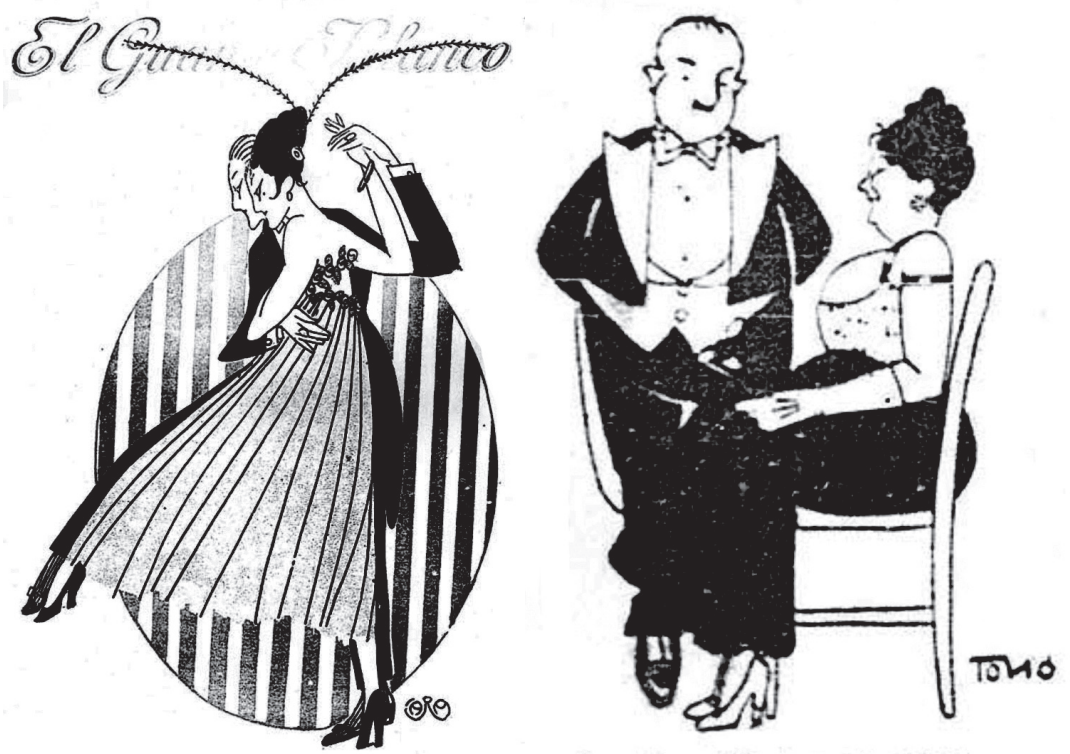

Dos dibujos de Antonio de Lara en El Guante Blanco, n 177 (16-I-1916) y La Traca, n 281 (17-I-1917) rubricados con diferentes firmas.

matiza, se redondea... A partir de $1913^{14}$, bosqueja un nuevo sello para singularizar sus trabajos: el de $\mathrm{TONO}^{15}$. Sin embargo, aún no parece del todo convencido: a veces une el primer apellido al nuevo seudónimo, y otras recupera la rúbrica de los inicios. En sus colaboraciones en la prensa de Valencia persiste está vacilación, e incluso después de su traslado a Madrid ${ }^{16}$.

Siendo un adolescente viaja a la capital y se esfuerza por abrirse camino en una ciudad desconocida: "con 17 años me vine a Madrid a triunfar", recuerda ${ }^{17}$.

14 La primera rúbrica con el seudónimo "Tono" aparece en el número 95 de La Traca (23-VIII-1913). Posteriormente localizamos otros ejemplos en: La Traca: número 245 (27-III-1916), número 254 (24-VI-1916) o número 281 (27-I-1917); de igual modo pueden verse ejemplos en el número 141 (7-III-1915) o el 161 (24-VII-1915) de El Guante Blanco.

15 Curiosamente, la última vez que firma con su apellido, "Lara", es en una caricatura que acompaña a un poema dedicado a Tono Saavedra en El Guante Blanco, 140 (14-II-1915). Su siguiente dibujo llevará el timbre de "Tono".

16 En los escasos estudios dedicados a Antonio de Lara se afirma erróneamente que el autor varía su firma al establecerse en Madrid.

17 Luis del Olmo, op. cit. Hasta el momento se databa la llegada de Tono a Madrid en 1919, un error cronológico sistematicamente repetido, ya que es entonces cuando 
Como era de esperar recae en La Botillería del Pombo, donde Ramón Gómez de la Serna guía su círculo literario. En aquel café de la calle Carretas conoce Antonio de Lara a Ramón, que de inmediato se fija en él: "yo me di cuenta de lo que iba a significar desde el primer momento, cuando no estaba aún radicado en su arte"18. El humor que caracteriza la obra de Tono es uno de sus rasgos intrínsecos. Su potencial lo trajo consigo desde Valencia, de ahí que el fino creador de las greguerías percibiera sin dificultad que "en el joven caricaturista estaba latente la gracia absurda que iba a dominar el porvenir"19.

Los comienzos en la capital son difíciles. Tras cinco años de búsqueda sin éxito, consigue una oportunidad en el diario El Liberal de la mano de Gómez de la Serna, donde publica una historieta cómica durante meses. Con esta carta de presentación comienza a vincularse a otras rotativas de gran tirada como Mundo Gráfico, Nuevo Mundo o La Esfera. A partir de 1921, de forma escalonada, los cinco humoristas coinciden en la redacción de Buen Humor. Se vislumbra, así, en las páginas del citado semanario, el germen de la "Otra Generación del 27", que fragmenta la línea seguida por el humor previo y plantea una nueva concepción. Tono y Mihura

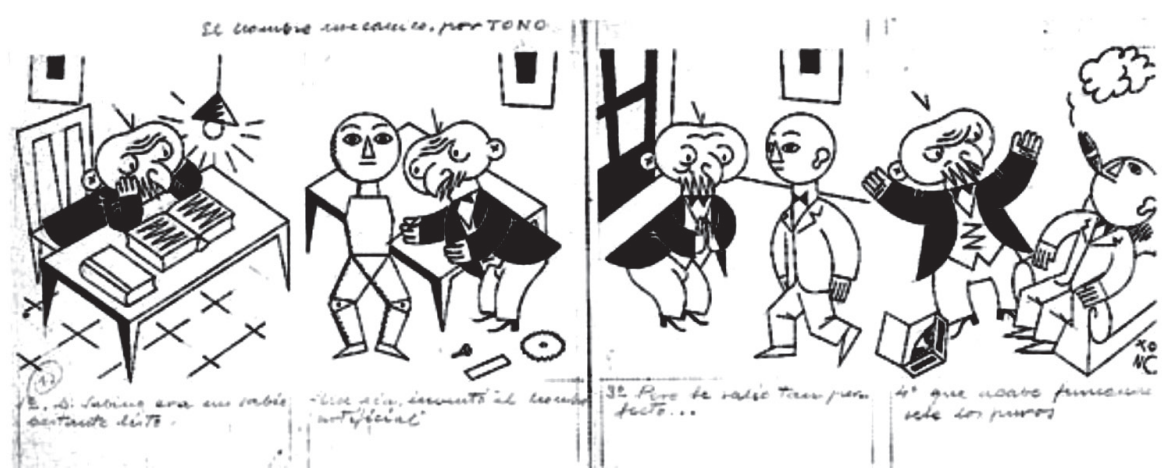

El hombre mecánico (tinta y lápiz, dos hojas 23,8 x 62,9cm). Historieta de Tono en sus comienzos como dibujante en Madrid. Extraída de VV.AA., Los humoristas del 27, Museo Nacional de Arte Reina Sofía, 2002, Madrid, p. 194.

comienza publicar sus trabajos. Sin embargo, el mismo autor aclara en esta entrevista el momento de su llegada y sus dificultades para comenzar su carrera en la capital.

18 Ramón Gómez de la Serna, "Laberinto del Nuevo Humorismo", Estafeta Literaria (Segunda Época), 73, Madrid, 8-XII-1956.

19 Ramón Gómez de la Serna, ibidem. 


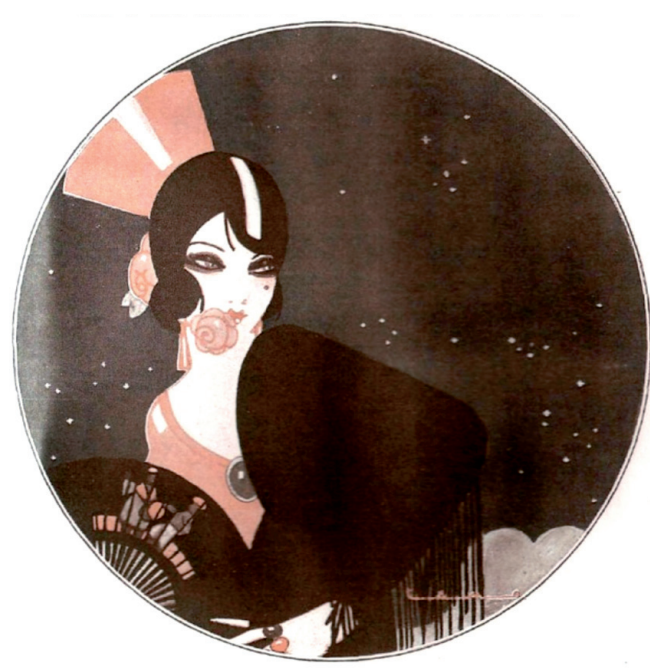

Portada de Benito, Vogue, abril de 1927

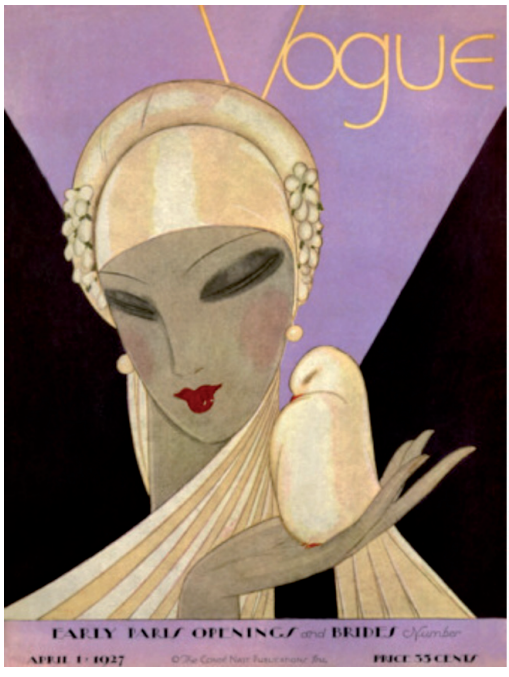

Ilustración de Tono para La Esfera, 1919

trabajan más enfocados hacia el humor gráfico, mientras que el resto de sus compañeros escriben pequeños artículos o cuentos ${ }^{20}$.

El mismo Antonio de Lara evalúa su etapa inicial como dibujante de este modo: "Hacia un dibujo que no me gustaba nada, y sigue sin gustarme, un dibujo muy rígido y muy antipático, pero como los pies gustaban empecéa publicar en todas partes $^{\prime 21}$. En sus primeras ilustraciones para la editorial Prensa Gráfica, o en los chistes de Buen Humor, sus figuras mantienen los referentes reales en cuanto a proporciones y rasgos; sus personajes son planos, pero existe la perspectiva y una decoración espacial acorde con la narración a la que acompañan.

Desde su estreno como ilustrador y humorista gráfico, Tono despliega dos estilos diferenciados: uno caricaturesco, más esquemático, del que se sirve para las historietas o chistes gráficos; y otro, decorativo y elegante, para las ilustraciones, con reminiscencias de la obra de García Benito, dibujante de Vogue y Vanity Fair desde $1912^{22}$.

20 "Al principio, los que bullíamos más seguidos de los jóvenes éramos Jardiel Poncela, López Rubio y yo. Tono y Mihura eran aún solamente dibujantes y crearon una forma nueva de la caricatura y el chiste”. Cf. José López Rubio, p. 13.

21 Tono se refiere a sus dibujos caricaturescos, no a las ilustraciones más decorativas, que comienza a realizar pocos meses después. Luis del Olmo, op. cit.

22 Benito es un exponente fundamental del art decó durante la estancia de Tono en Francia a partir de 1923. Hacia 1918, el ilustrador vallisoletano expone con asiduidad en el 
En 1923, Antonio Lara decide ampliar sus horizontes y viaja a París. Siguiendo los consejos de amigos, que antes habían recorrido el mismo sendero, visita las distintas redacciones con una carpeta bajo el brazo plagada de dibujos. Rápidamente es contratado en Le Rire y posteriormente en Le Sourire, Candide y Ric et Rac, donde colaborará asiduamente. De este modo lo recuerda el humorista jíenense:

El director, (de Le Rire) un importante escritor francés, se interesó rápidamente por mis dibujos, se quedó con alguno y me encargó que hiciera algunas portadas para Le Sourire, que pertenecía a la misma editorial. Entonces todo fue coser y cantar, dibujar y visitar ${ }^{23}$.

El contacto con los pintores, arquitectos y escultores más vanguardistas del momento influirá en su trazo de forma decisiva. De la torpe rigidez de los inicios, fruto de la inexperiencia ${ }^{24}$, evoluciona hacia una dureza voluntaria (siempre más flexible en los figurines de modas y más geométrica en los chistes). En la vertiente de la caricatura y el humor gráfico, sus trabajos presentan figuras humanas compuestas a partir de círculos, triángulos y escenas con grandes contrapicados, faltas de perspectiva, en las que destacan fuertes deudas cubistas, surrealistas y, en menor medida, dadaístas y constructivistas. López Rubio explica cómo procedía su amigo para esbozar aquellas exactas y disparatadas formas: "usaba reglas, tiralíneas y compás para hacer las señoras gordas" 25 . Su arte despierta un gran interés en Francia, razón por la que comienza a ser considerado el creador del geometrismo español. Tanto es así que el francés Grove secundaría las ideas gráficas de Tono.

Como ilustrador sigue las tendencias marcadas por el art decó y algunas de sus portadas le hacen popular fuera de nuestras fronteras. También el cartelismo francés, en su vertiente más futurista y mecánica, se deja sentir en sus diseños y las figuras empiezan a diferenciarse del resto de la super-

Salon d'Automne o en la Societé Nationale des Beaux Arts; y su labor en Vogue o Vanity Fair se extiende desde 1921 a 1940. Resulta, por tanto, muy factible que Tono conociera los trazos de su compatriota a través de la prensa, antes de su traslado a París.

23 Marino Gómez Santos, "Tono cuenta su vida", en la sección "Pequeña historia de grandes personajes", Pueblo, 9-XII-1959, p. 18.

24 Tono declara que recurrió a las reglas, compases y tiralíneas para controlar su mal pulso. Luis del Olmo, op. cit.

25 José López Rubio, op. cit., p. 20. 


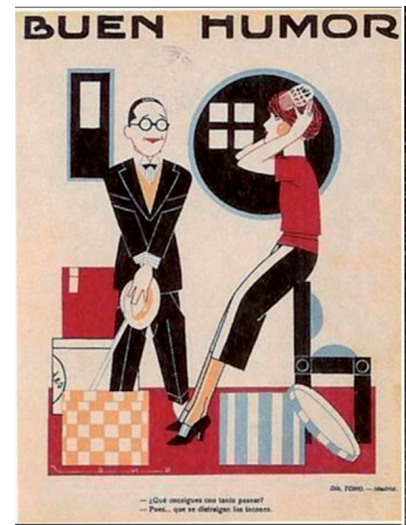

Buen Humor, n 39, 1922

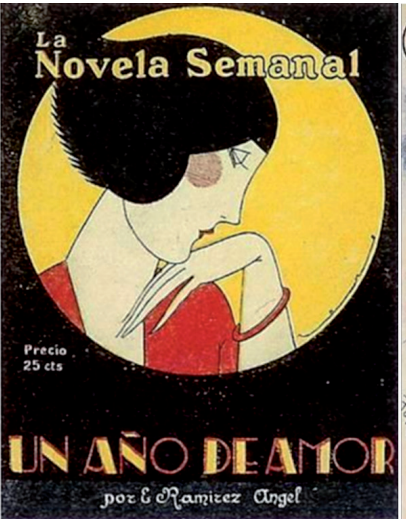

La novela semanal, $n^{\circ} 124$, Un año de amor de Emiliano Ramírez Ángel, portada de Tono, Madrid, Prensa Gráfica, 1923

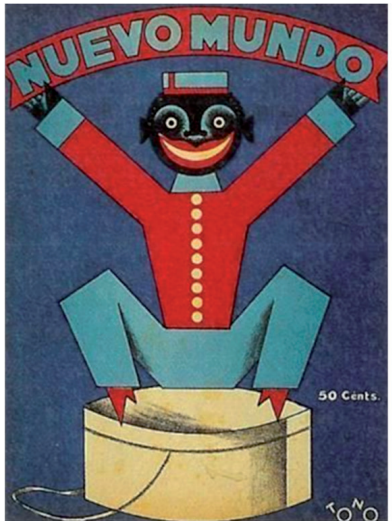

Nuevo Mundo, $\mathrm{n}^{\circ} 1707,1926$

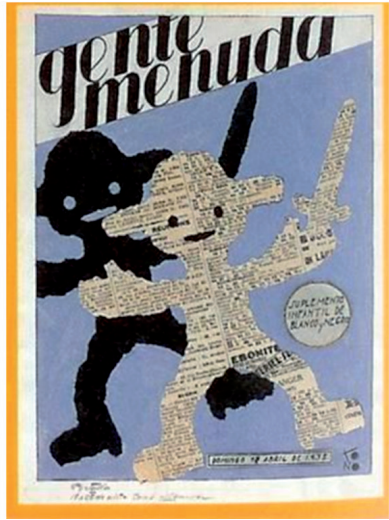

Gente Menuda, 17-IV-1932

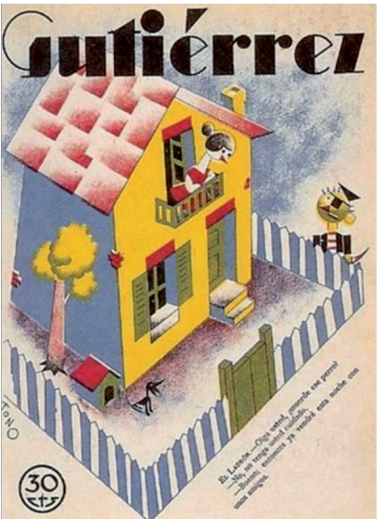

Gutiérrez, n 12, 1927

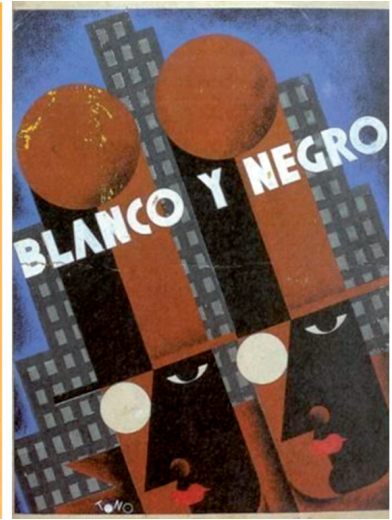

Blanco y Negro, 1932.

ficie, a guisa de recortes pegados sobre el papel. Hasta 1930, sus dibujos siguen incluyendo los contrapicados que caracterizaron su etapa francesa. Solo posteriormente utiliza figuras recortadas y adheridas sobre un fondo distinto, haciendo sus personajes más planos si cabe. El aprendizaje de Antonio de Lara en la capital francesa es fundamental para su desarrollo como artista plástico. No en vano, en 1925 se le concede el Diploma de Honor en la Exposición Internacional de Artes Decorativas de París.

Tono se establece en Francia durante ocho años, pero frecuenta Madrid, lo que le permite participar en el segundo punto de encuentro para nuestro 

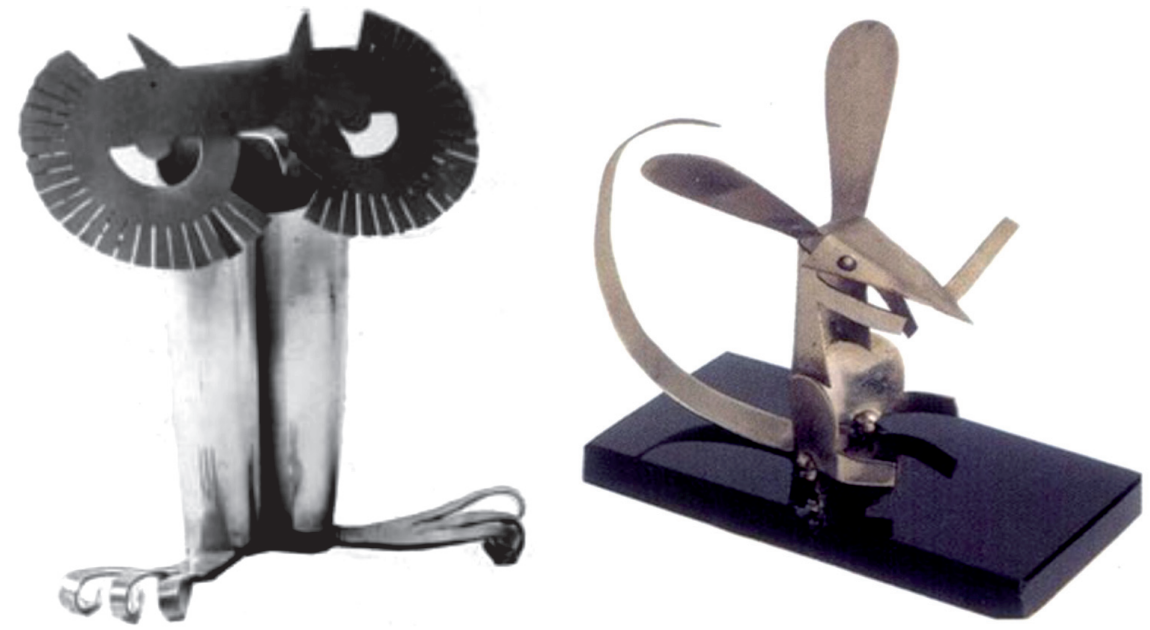

Ratón y búho, esculturas metálicas de Tono, expuestas en el Círculo de Bellas Artes, 1932.

quinteto de humoristas. Todos ellos, junto con el director del proyecto, K-Hito, fundan en 1927 el semanario Gutiérrez, donde sin abandonar el chiste gráfico comienzan a redactar pequeños textos. Mihura y Tono se inclinan entonces por un humor más disparatado y menos formal ${ }^{26}$. La publicación se convierte en la revista más leída de España y en sus páginas se cristaliza la nueva concepción de los humoristas como "Humor Nuevo".

En su segunda y breve estancia en tierras galas, separada de la inicial por la experiencia hollywoodiense, vuelve a reencontrarse con la escultura. Esta vez utiliza un material vanguardista: la chapa de aluminio. Sus piezas representan animales reales e imágenes cotidianas, a partir del símbolo futurista, deshumanizado, frío y semi-rígido. Su convivencia con el escultor José de Creeft ${ }^{27}$-también anti-academicista- es cardinal

26 "Cuando Edgar Neville, Tono y yo empezamos a escribir, compramos una Gramática para los tres", en Miguel Mihura, "Periodismo de humor", Enciclopedia de Periodismo, Madrid, Moguer, 1996, pp. 435-447 (p. 439).

27 Recordemos que De Creeft realizaba esculturas "para divertirse y entretener a los amigos, utiliza todo tipio de materiales como alambres, hierros viejos, chatarra, papel, corteza de árbol, etc". Cf. José Ma Alix Trueba, "José de Creeft, un escultor universal", Wad-Al-Hayara: Revista de Estudios de Guadalajara, 8 (1981), pp. 483-494 (p. 490). 

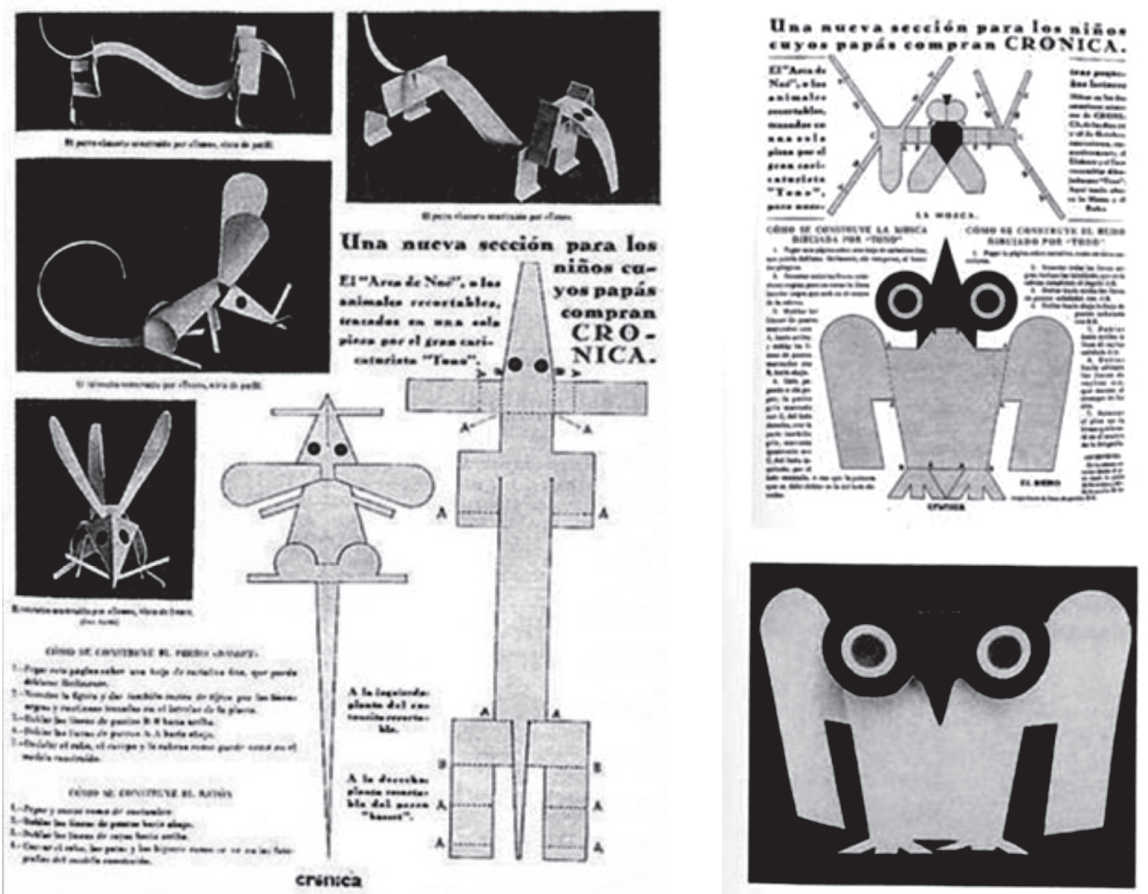

Ratón y Búho, dos de los recortables aparecidos en Crónica, Ric et Rac, y Berliner Illustrieter

para la creación de sus esculturas metálicas, expuestas con gran éxito en el madrileño Círculo de Bellas Artes en $1932^{28}$.

La misma idea, llevada después al papel con recortables que se pliegan hasta formar animales, obtendrá gran éxito en prensa bajo el título de $E l$ Arca de Noé. Curiosamente, el formato de la idea, o sea, la entrega de una figura con cada periódico hasta reunir un zoo de más de sesenta ejemplares, es muy similar a la iniciativa de José López Rubio en el semanario infantil Pinocho (1925), en cuya sección “Teatro Pinocho” se regalaba cada semana un personaje, hasta coleccionar toda una compañía escénica. Se diría que Tono mezcla en su coctelera las esculturas de Creeft en chatarra reciclada y el "Teatro Pinocho" de López Rubio, los agita y nos brinda

28 Las esculturas se vendieron en su totalidad y revistas como Viviendas, en su número 33, dedicaron un artículo comentando la novedosa tendencia decorativa. 


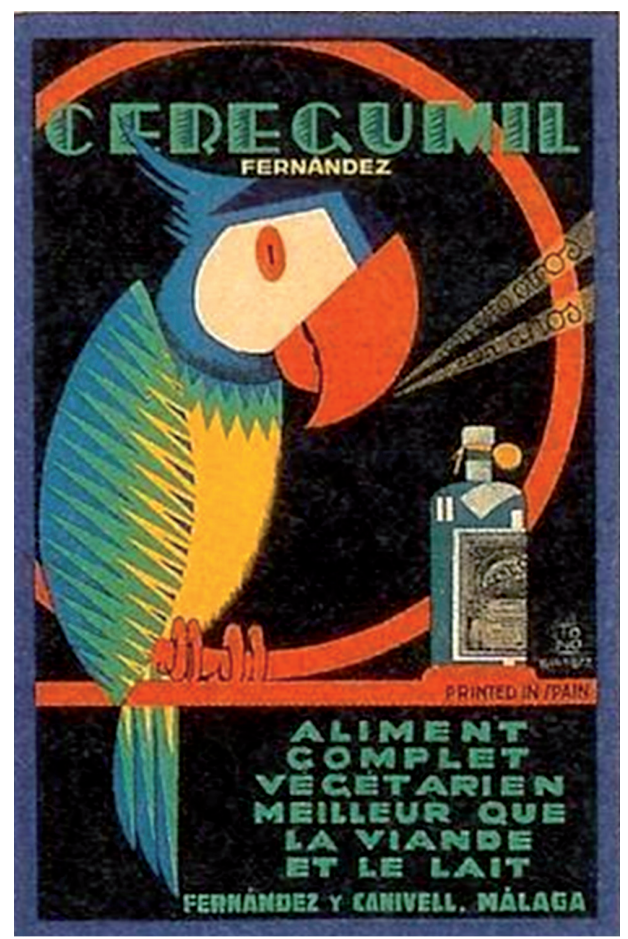

los recortables tridimensionales en una sola pieza publicados en Crónica (España), Ric et Rac (Francia) y Berliner Illustrieter (Alemania).

Durante la década de permanencia en Francia, Antonio de Lara también fragua una brillante carrera como cartelista. En este sentido, sus dibujos le reportaron varios premios que evoca con su característico humor:

Puedo decir con la frente muy alta, la nariz muy alta y el sombrero más alto que la nariz y la frente, que conseguí bastantes premios, entre los que recuerdo el de la Lotería de la Ciudad Universitaria, el del loro del Ceregumil, todavía en vigor; el del libro español en Buenos Aires, uno de la cruzada contra el paludismo en un concurso de la casa Bayer, cuyo premio nunca llegó a mis manos ${ }^{29}$.

29 Marino Gómez Santos, “Tono cuenta su vida”, en la sección "Pequeña historia de grandes personajes", Pueblo, 11-XII-1959, p. 18. 


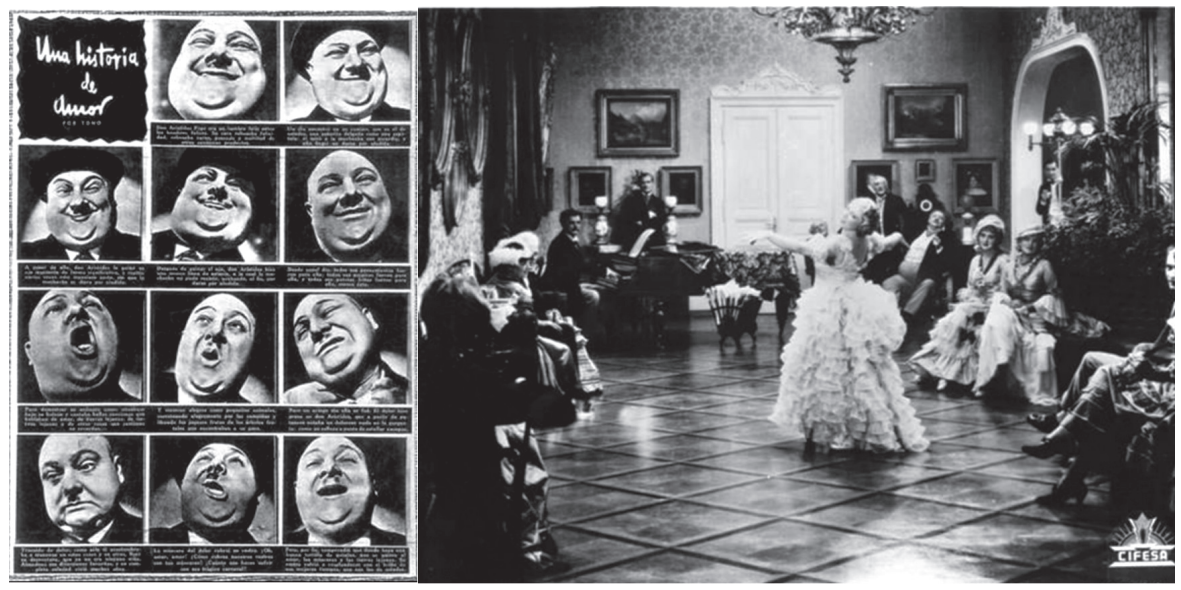

Sección de Tono en La Codorniz, 111 (1943); Fotograma de Un bigote para dos. Reproducimos el diálogo que acompaña a este plano: "- ¡Qué bien baila! / - Sí; y eso que no tiene más que dos pies en las piernas".

En la guerra civil española Antonio de Lara se refugia en la zona nacional, al igual que Miguel Mihura y Edgar Neville. Escribirá entonces en varias revistas editadas por el Comisariado del Guerra: La Ametralladora, dirigida por Mihura, continuadora de la línea abierta por Buen Humor y Gutiérrez; y Vértice, en la que Tono ofició como director artístico. A lo largo del periodo bélico y en los años posteriores, ya en Madrid, el jienense modifica su estilo como dibujante, abandonando por completo el compás y las reglas. Sus dibujos más surrealistas empiezan a ser la constante, flotando ajenos a cualquier perspectiva. Las representaciones humanas no son ya un conjunto de geometrías, sino solo una figura: normalmente un triangulo representa la esencia más absurda del ser humano, causando furor entre los dibujantes madrileños

De acuerdo con las nuevas vanguardias, incluye elementos narrativos ya preexistentes en sus obras, como las fotografías de prensa antigua a las que añade un pie disparatado. En estas instantáneas de principios de siglo, para las que acuña algunas de sus "salidas de tono", radica el germen de lo que cristalizará en el filme Un bigote para dos (1940). Recordemos que el humorista llegó a definir el cine como una historieta donde las viñetas se suceden. En esta película, Mihura y Lara suprimieron la banda sonora original, añadiendo a las secuencias enloquecidos diálogos que, 
por contraste entre la imagen antigua y la actualidad del guión, suscitan la risa del espectador. Exactamente igual se construyen "las fotos con pie".

En los años cuarenta, Antonio de Lara mantiene su estilo como dibujante. Durante la etapa de La Codorniz los dibujos de Tono y Mihura pueden confundirse a primera vista, quizás por su intensa relación personal y laboral. Este "estancamiento" le permite utilizar ideas, chistes, historietas o relatos, editados en otros lugares antes de la guerra.

A partir de 1955, participa habitualmente en la revista de humor Don José, aunque sus aportaciones no sufran cambios estimables. Hay que esperar a 1960 para que Tono renueve otra vez su estilo con trazos voluntariamente inseguros: sus personajes se apartan de la rigidez y restringe la expresión de la mirada a un simple punto. Con todo, más allá de las sucesivas evoluciones, se puede extraer una serie de denominadores en común: una ejecución cuidadosa, pensada, dibujos influenciados por el cubismo y su preferencia por los personajes planos, deshumanizados y deformados. Por estas fechas recibe el Premio Mingote (1968) y el Premio Paleta de Agromán del Humor (1969).

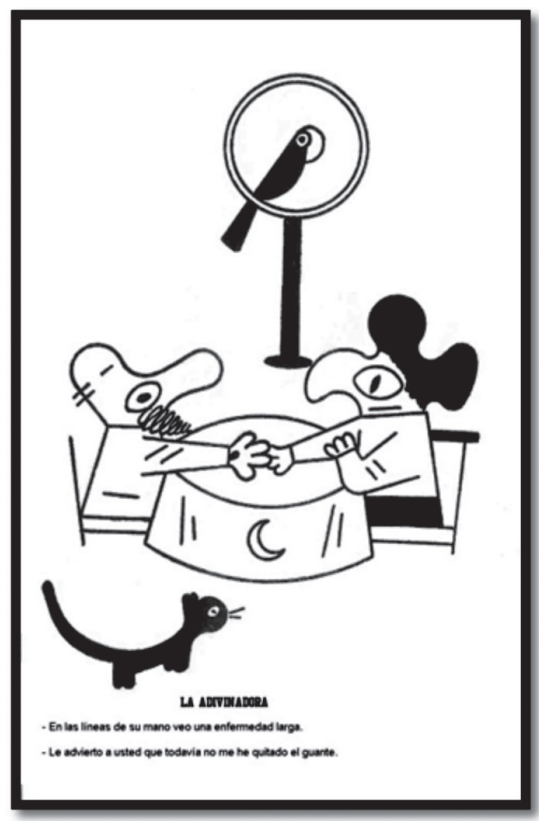

100 Tonerias, Nueva Editorial, 1938. "La adivinadora: -En las líneas de la mano veo una enfermedad larga / -Le advierto que todavía no me he quitado el guante".

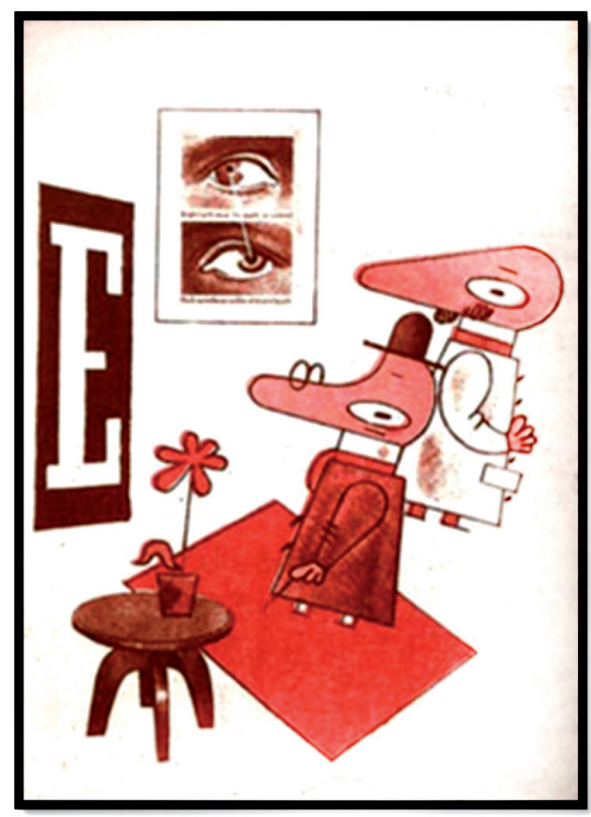

La Codorniz, 3 (22-IV-1941). "-Ve usted esa letra. / -Sí, señora". 


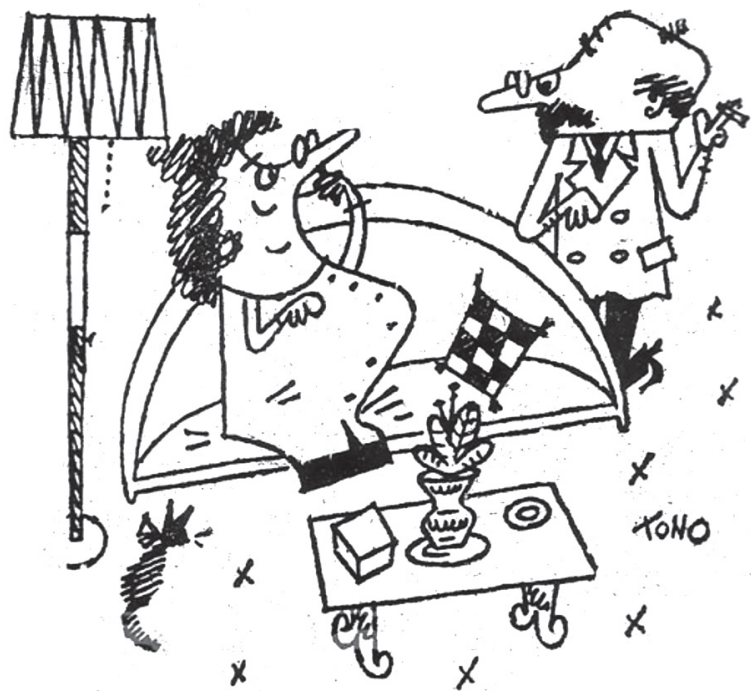

“- Pues sí, Don Federico; ayer nos llevó a Toledo un americano amigo nuestro y ¡No sabe usted lo que nos gustó!”30.

Lara nunca deja a la improvisación o a la intuición lo que pretende expresar con sus trazos: "El dibujo es siempre lo que Tono ha querido que sea: el azar no interviene en su trabajo"31. Visual y verbalmente plantea de un modo innovador el rechazo de los tópicos, la ridiculización de lo burgués y el ataque contra el lugar común. Todas las deshumanizaciones "tonianas", al menos en su humor gráfico, ilustran con nitidez sus puntos de vista: un señor es un triángulo isósceles, un respetable marido flota en el techo de salón... Un planteamiento reductor y pueril que provoca la sonrisa, aleja la seriedad del tema en cuestión y quiebra la solemnidad que suele rodear al arte. Parafraseando a Ramón Gómez de la Serna: "Caricaturas que son como el eco de su plante frente a la vida, y sus sorpresas" 32 .

El método de trabajo de Tono como humorista gráfico acostumbra a ser el mismo: una frase ingeniosa le sobreviene y después añade el dibujo que glosará el texto. De ahí que muchos pies de viñeta sean autónomos

30 Informaciones, 17-IV-1967. Chiste galardonado con el Premio Mingote en 1968.

31 Iván Tubau, De Tono a Perich. El chiste gráfico en la prensa española de la posguerra (1939-1969), Madrid, Fundación Juan March / Editorial Guadarrama, 1973, p. 162.

32 Ramón Gómez de la Serna, "Laberinto del nuevo humorismo", op.cit. 
por sí mismos: no precisan de la ilustración, las figuras funcionan como complemento de las frases. En otros chistes se produce una retroalimentación entre palabra e imagen, de manera que una no funciona sin la otra. En este sentido, Iván Tubau sostiene que los dibujos de Tono son los únicos que pueden representar sus explosivos diálogos, pues los estilos de otros autores no representan el espíritu "toniano":

Solo con los muñecos de Tono, adquieren los chistes de Tono su auténtica dimensión [...]. Sus textos en La Codorniz ilustrados por Picó, o los de Semana ilustrados por Alcocer adquieren una dimensión distinta, menos coherente que la de los ilustrados por el propio autor ${ }^{33}$.

Como hemos mencionado, entre las ocupaciones de Tono se cuenta la dirección de revistas. Concretamente de tres: Vértice, Cámara y Foco. Su primera incursión data de abril de 1937, desde las páginas de Vértice, costosa apuesta editorial de Falange. La deslumbrante publicación lo nombra subdirector y posteriormente director artístico hasta $1940^{34}$. Vértice posee una maqueta cuidadísima y una composición clara y geométrica, en la órbita de las últimas tendencias de semanarios inspirados en la nueva tipografía. Quizás la opinión Romley ${ }^{35}$, especialista en temas decorativos del semanario Blanco y Negro durante los años treinta, también influyera en el estilo que adoptó Antonio de Lara. En esta misma revista cultiva una relación constante con la fotografía, que conservará el resto de su carrera. Así, nos topamos con secciones dedicadas, por ejemplo, a Man Ray, a quien Tono conoció durante sus veranos en la comarca francesa de San Juan de Luz.

33 Iván Tubau, El humor gráfico en la prensa del franquismo, Barcelona, Editorial Mitre, 1987, p. 124

34 En el número 5 de la revista Vértice (septiembre-octubre de 1937), Tono consta acreditado como "confeccionador". Es en el número 6 de la misma publicación (noviembre de 1937) cuando se le cita como "director artístico". Tono fue el director artístico de Vértice hasta 1940, aunque se publicó hasta 1946. El cargo pasó a otra persona que firma con las iniciales A.T.C., coincidiendo precisamente con el cambio en la dirección de la revista que presidirá Samuel Ros.

35 Romley fue uno de los directores de Vértice. Fundó tras la guerra la revista Horizontes, en la que Tono también colaboró. 


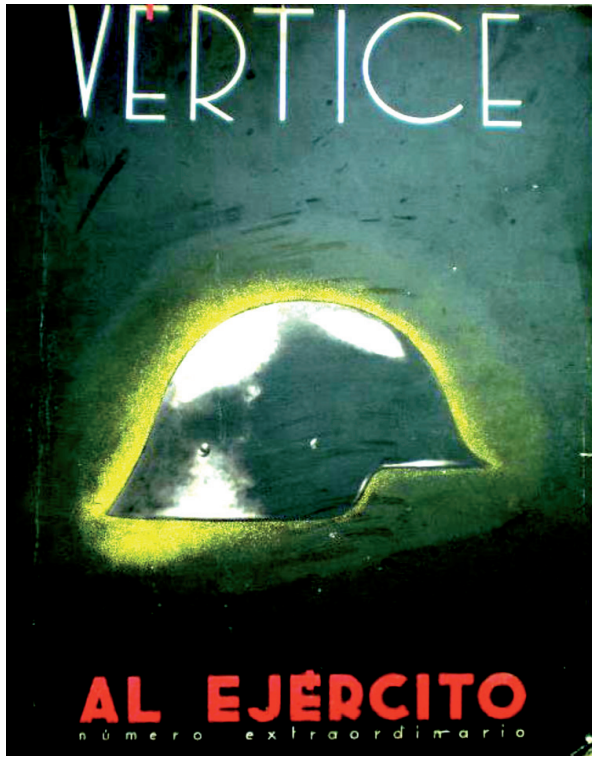

Vértice, 4, julio-agosto 1937

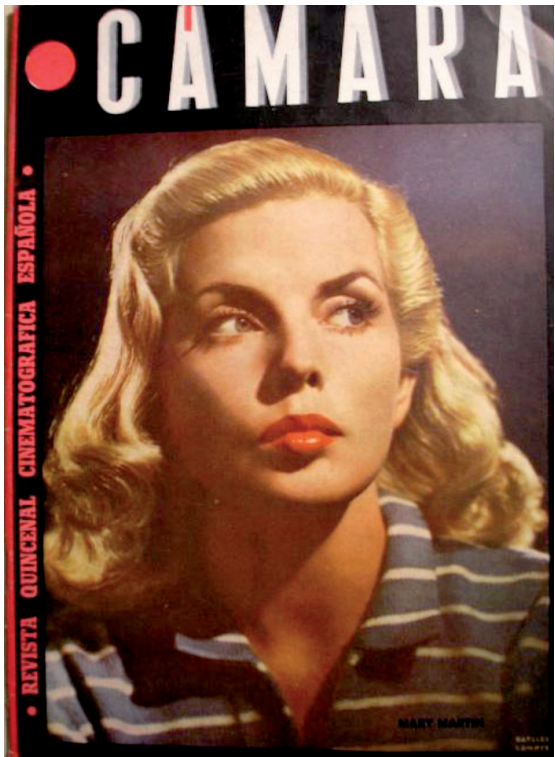

Cámara, 53, 1945 (portada Mari Martín)

Terminada la contienda española y asentado de nuevo en Madrid, Tono funda Cámara (1945), la única revista cinematográfica no falangista impresa regularmente durante el franquismo hasta la llegada de Fotogramas en 1946. Los reportajes en torno al mundo del celuloide, pero fundamentalmente los dedicados a actores, tanto españoles como extranjeros, le granjearon a la revista una enorme popularidad. Tono se encarga también de su dirección hasta agosto de $1946^{36}$, si bien sus números perviven hasta 1947. Cámara propuso un atractivo continente al lector y llega a instituirse como una de las más prestigiosas publicaciones de la época sobre el séptimo arte. Posteriormente, en 1952, Lara auspicia y dirige Foco. El mundo en imágenes, donde el radio periodístico se abre más allá del cine. La revista utiliza una moderna maquetación siguiendo el estilo de la norteamericana Life, pero su andadura es breve y desaparece a comienzos de 1954.

En la madurez le ocupan su pasión por la pintura y la escultura. Con ellas distrae sus ratos de ocio sin más pretensión. Las amistades le animan

36 VV. AA., Diccionario de Cine Español. Academia de las Artes y las Ciencias Cinematográficas de España, ed., José Luis Borau, Madrid, Alianza, 1998, p. 856. 
a que se profesionalice organizando alguna exposición de sus obras, pero no llegará a proponérselo ${ }^{37}$. A fines de los setenta, la pintura matérica y el informalismo siguen en auge y durante una larga temporada acude a la casa-estudio del pintor José Caballero para conocer distintos tipos de mezclas e introducir en sus cuadros materiales con volumen. Vuelve a ocuparse de la escultura construyendo estructuras con plásticos, metal, colores y pintura, a partir de figuras geométricas, como, por ejemplo, esferas transparentes llenas de elementos coloristas de diferentes tamaños.

$\mathrm{Su}$ afición favorita, a la que dedica mucho tiempo desde joven, es la construcción de artilugios: "Yo verdaderamente tengo alma de inventor", rememora el autor en una entrevista ${ }^{38}$. Algunos de ellos tienen una estética interesante: una mano de gran tamaño que mueve los dedos, una lima de uñas con motor, un adaptador para conducir el coche... Sin duda, su capacidad constante de renovación y búsqueda le proclaman variopinto inventor. Y si nos ceñimos al testimonio de Mingote, compañero de invenciones posibles e imposibles, observamos que representan uno de sus puntos de apoyo para otro tipo de artes:

Tono inventó más cosas que ningún otro inventor que yo conozca. Inventó la revolución en la caricatura convirtiendo los trapecios isósceles en notarios, en domadores de tigres, en lo que hiciera falta, y consiguió caricaturizar lo que nunca se había caricaturizado: por ejemplo, un huevo, un huevo concreto, del que Tono sabía descubrir lo que le diferenciaba de todos los demás huevos del mundo ${ }^{39}$.

Sus compañeros y amigos organizaron en los últimos días de abril de 1976 un homenaje y, conociendo su desbordante inventiva, le regalaron un reloj para que lo transformase en una lavadora.

Antonio de Lara, de carismática personalidad, fue fiel al humorismo tanto en su vida como en obra, mostrándonos las ocurrencias más dispa-

37 Entrevista realizada por Gema Fernández-Hoya a María Fernanda Thomas de Carranza (viuda del pintor José Caballero), Madrid, 23-VIII-2010.

38 Marino Gómez Santos, "Tono cuenta su vida", en la sección "Pequeña historia de grandes personajes", Pueblo, 11-XII-1959, p. 18.

39 Antonio Mingote, Hombre solo, hombre atónito: gritos sin palabras de Antonio Mingote, Madrid, Círculo de Lectores, 1988, p. 85 
ratadas del "Humor Nuevo". Se convirtió en uno de los renovadores del humor contemporáneo con brillantes trabajos, que resultan aún más sorprendentes considerando la magnitud del salto social e intelectual que efectúa, al situarse en la élite cultural de su tiempo, sin más recursos que sus aptitudes congénitas. Injustamente, el legado de Tono se desvanecía sigilosamente con el devenir de los años, pero, por suerte, su ingenio perdura en la memoria colectiva a través de aquellos insospechados chistes gráficos.

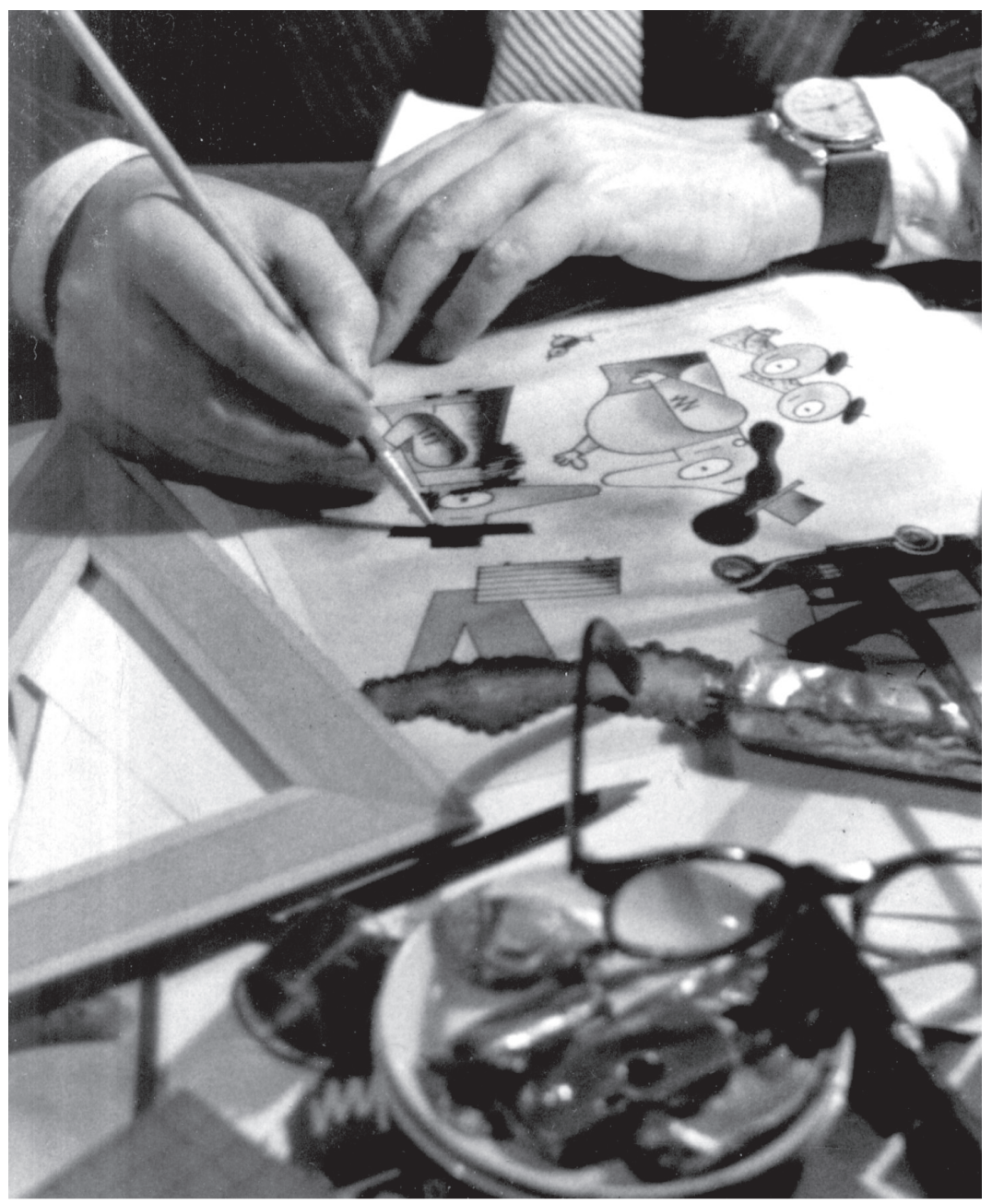

